\title{
Multi-scale forcing and the formation of subtropical desert and monsoon
}

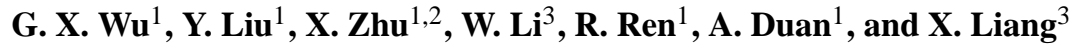 \\ ${ }^{1}$ State Key Laboratory of Numerical Modeling for Atmospheric Sciences and Geophysical Fluid Dynamics (LASG), Institute \\ of Atmospheric Physics (IAP), Chinese Academy of Sciences, Beijing 100029, China \\ ${ }^{2}$ Graduate University of Chinese Academy of Sciences, Beijing, China \\ ${ }^{3}$ National Climate Center, China Meteorological Administration, Beijing 100081, China
}

Received: 19 March 2009 - Revised: 30 July 2009 - Accepted: 7 September 2009 - Published: 29 September 2009

\begin{abstract}
This study investigates three types of atmospheric forcing across the summertime subtropics that are shown to contribute in various ways to the occurrence of dry and wet climates in the subtropics. To explain the formation of desert over the western parts of continents and monsoon over the eastern parts, we propose a new mechanism of positive feedback between diabatic heating and vorticity generation that occurs via meridional advection of planetary vorticity and temperature. Monsoon and desert are demonstrated to coexist as twin features of multi-scale forcing, as follows.

First, continent-scale heating over land and cooling over ocean induce the ascent of air over the eastern parts of continents and western parts of oceans, and descent over eastern parts of oceans and western parts of continents. Second, local-scale sea-breeze forcing along coastal regions enhances air descent over eastern parts of oceans and ascent over eastern parts of continents. This leads to the formation of the well-defined summertime subtropical LOSECOD quadruplet-heating pattern across each continent and adjacent oceans, with long-wave radiative cooling (LO) over eastern parts of oceans, sensible heating (SE) over western parts of continents, condensation heating (CO) over eastern parts of continents, and double dominant heating (D: LO+CO) over western parts of oceans. Such a quadruplet heating pattern corresponds to a dry climate over the western parts of continents and a wet climate over eastern parts. Third, regional-scale orographic-uplift-heating generates poleward ascending flow to the east of orography and equatorward descending flow to the west.
\end{abstract}

The Tibetan Plateau (TP) is located over the eastern Eurasian continent. The TP-forced circulation pattern is in phase with that produced by continental-scale forcing, and the strongest monsoon and largest deserts are formed over

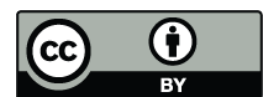

Correspondence to: Y. Liu

(lym@lasg.iap.ac.cn) the Afro-Eurasian Continent. In contrast, the Rockies and the Andes are located over the western parts of their respective continents, and orography-induced ascent is separated from ascent due to continental-scale forcing. Accordingly, the deserts and monsoon climate over these continents are not as strongly developed as those over the Eurasian Continent.

A new mechanism of positive feedback between diabatic heating and vorticity generation, which occurs via meridional transfer of heat and planetary vorticity, is proposed as a means of explaining the formation of subtropical desert and monsoon. Strong low-level longwave radiative cooling over eastern parts of oceans and strong surface sensible heating on western parts of continents generate negative vorticity that is balanced by positive planetary vorticity advection from high latitudes. The equatorward flow generated over eastern parts of oceans produces cold sea-surface temperature and stable stratification, leading in turn to the formation of low stratus clouds and the maintenance of strong in situ longwave radiative cooling. The equatorward flow over western parts of continents carries cold, dry air, thereby enhancing local sensible heating as well as moisture release from the underlying soil. These factors result in a dry desert climate. Over the eastern parts of continents, condensation heating generates positive vorticity in the lower troposphere, which is balanced by negative planetary vorticity advection of the meridional flow from low latitudes. The flow brings warm and moist air, thereby enhancing local convective instability and condensation heating associated with rainfall. These factors produce a wet monsoonal climate. Overall, our results demonstrate that subtropical desert and monsoon coexist as a consequence of multi-scale forcing along the subtropics.

Keywords. Meteorology and atmospheric dynamics (Climatology; General circulation; Precipitation)

Published by Copernicus Publications on behalf of the European Geosciences Union. 


\section{Introduction}

Compared with the large number of studies on the formation of monsoons (e.g., Webster et al., 1998; Wang et al., 2006), few have investigated the dynamics of desert formation. Prior to the 1970s, the formation of desert had long been attributed to the descending arm of the Hadley Cell along the subtropics: its adiabatic heating was thought to reduce the atmospheric relative humidity, while the associated horizontal divergence near the surface suppressed the formation of cloud, resulting in subtropical aridity. However, severe subtropical arid climates occur during summer when the Hadley Cell is weakest, whereas such aridity is weak during winter when the Hadley Cell is strongest. In addition, many moist, monsoonal areas also exist within the subtropics. Therefore, the climate in such areas cannot be readily explained in terms of the traditional view (i.e., the Hadley Cell).

Charney (1975) proposed a local biosphere-albedoatmosphere feedback mechanism to explain the enhancement of the Sahel Desert, arguing that over-grazing in arid areas increases surface albedo, and that radiative heat loss over desert areas is compensated by adiabatic descent, which in return results in a decrease in relative humidity and leads to desertification. Such a localized mechanism ignores the influence of advection, and is applicable only to tropical areas (e.g., Bounoua and Krishnamurti, 1991), where the Burger Number is large (Hoskins, 1986).

Most deserts are found in the subtropics, where the Burger Number is close to one. In these areas, the advection of heat is comparable with adiabatic heating in balancing external heating, and cannot be ignored when considering the formation of desert. Yang et al. (1992) proposed a linkage between aridity and convection via a closed overturning "Walker Cell." Using trajectory analysis, Rodwell and Hoskins (1996) found that descent over the eastern Sahara, Mediterranean, and Kyzylkum Desert are mainly of mid-latitude origin (their Fig. 9) rather than resulting from Walker-type circulation. The authors proposed a monsoondesert mechanism for desertification whereby remote diabatic heating in the Asian monsoon region induces a Rossbywave pattern to the west, resulting in clear sky and creating a local diabatic enhancement "which effectively doubles the strength of descent."

Across the subtropics, zonal advection of vorticity or temperature is weak. In the present study, after investigating the characteristics of atmospheric forcing across the summer subtropics at different spatial scales, a new mechanism is proposed for the enhancement of dry and moist climate, involving a positive feedback between diabatic heating and vorticity generation via meridional advection of planetary vorticity and temperature. With reference to this mechanism, desert over the western parts of continents and monsoon over the eastern parts of continents are demonstrated to represent coexisting twin features of a single system.
The remainder of the manuscript is organized as follows. In Sect. 2, we briefly introduce the model and data used in the present analysis. Large-scale continental forcing and localscale coastal sea-breeze forcing in summer are analyzed in Sects. 3 and 4, respectively, and are used as a basis upon which to explain the formation of summertime quadruplet heating across each subtropical continent and its adjoining oceans. New, local positive feedback mechanisms for the formation of monsoon and desert are presented in Sect. 5, and the impacts of regional-scale mountain forcing on subtropical arid and wet climates are considered in Sect. 6. Section 7 provides a summary of the main findings.

\section{Data and model}

We employed the reanalysis of the National Centers for Environment Prediction/National Center for Atmospheric Research (NCEP/NCAR; Kalnay et al., 1996) and Xie-Arkin data (Xie and Arkin, 1996) from 1980 to 1997 to investigate the separate and combined impacts of different thermal forcings on the formation of monsoon and desert. Diabatic heating in the NECP/NCAR reanalysis is not observation data, but the product of a general circulation model (GCM) that depends on physical parameterization schemes (Newman et al., 2000). Comparisons among NCEP heating, Q1 from ECMWF data (Nigam et al., 2000; Rodwell and Hoskins, 2001), and TOGA data (Lin and Johnson, 1996) reveal similar horizontal distributions of column-integrated heating and the vertical heating profile.

Duan and Wu (2005) compared NCEP reanalysis data and two other data sets: observations from six Automatic Weather Stations upon the Tibetan Plateau (abbreviated as TP hereafter) from July 1993 to March 1999 (Li et al., 2001), and GAME-IOP reanalysis data from 1 April to 31 October 1998 , as compiled by the Japan Meteorological Research Institute and the Japanese Meteorological Agency (Yamazaki et al., 2000a, b; see also http://game.suiri.tsukuba. ac.jp/cdroms/CD-ROM.html). The comparison revealed that the surface sensible heat flux and latent heat flux provided by NCEP/NCAR agree with the AWS data, and there is no significant difference in spatial/temporal variations and magnitude between the NCEP/NCAR and GAME-IOP daily data sets. This finding validates the use of the NCEP/NCAR reanalysis in the present study, although a degree of caution is required because AWS and GAME-IOP data have limited spatial/temporal coverage.

Numerical experiments were performed using the Global Ocean-Atmosphere-Land System model developed at LASG (IAP/LASG GOALS; Wu et al., 1997a, 2003). The atmospheric component is a spectral GCM with nine vertical levels in $\sigma$-coordinates and that is rhomboidally truncated at wave number 42 in the horizontal. Land-surface processes are represented by the SSiB model (Xue et al., 1991), which has previously been implemented in the atmospheric 
component (Liu and Wu, 1997). The GOALS climate model can simulate the mean climate reasonably well and has been used in climate studies for a variety of purposes (IPCC, 2001; Kang et al., 2002).

In this study, the required sea surface temperature (SST) and sea ice are prescribed based on climate mean observation data for the period 1979-1988, as compiled for the Atmospheric Model Intercomparison Program (AMIP). Because the adjustment period measured by the global mean surface temperature is about 6 months for each experiment (data not shown), all the experiments in this study are integrated for 12 model years, and the monthly means for the last 10 years are calculated for comparison.

\section{Land-sea distribution and continental-scale LOSECOD heating}

The global distributions of column-integrated total diabatic heating in January and July are shown in Fig. 1a and b, respectively. The total diabatic heating includes diffusive sensible heating (SE), condensation latent heating (CO), longwave radiative cooling (LO), and short-wave radiative heating (SH). The atmosphere along the equator and in nearequator tropical areas is a strong heating source except over the eastern Pacific and Atlantic, where it becomes a permanent heat sink in association with the existence of in situ cold tongues of SST. There is generally no apparent seasonal change in these tropical areas. In contrast to the tropics, a marked seasonal change in total diabatic heating occurs in the extra-tropics. In January (Fig. 1a), during the Northern Hemisphere winter, atmospheric heating is positive over oceans, but negative over continents. The Southern Hemisphere is in summer during January, and the atmosphere is characterized by heating over continents and cooling over oceans. In the northern extra-tropics during July (Fig. 1b), atmospheric heating occurs over continents, whereas cooling occurs over oceans. The Southern Hemisphere is in winter at this time, and atmospheric heating over continents is negative, while weak atmospheric heating is observed over mid-latitude oceans. In summary, the total heating in the summer extra-tropics is positive over continents, but negative over oceans:

$$
\int_{0}^{P_{0}} Q \frac{d p}{g}>0, \text { over continents }
$$

$$
\int_{0}^{P_{0}} Q \frac{d p}{g}<0, \text { over oceans, }
$$

where $Q$ represents total heating (= $\mathrm{SE}+\mathrm{CO}+\mathrm{LO}+\mathrm{SH}), P_{0}$ is surface pressure, and $g$ is acceleration due to gravity.

According to the $P V-\theta$ view (Hoskins, 1991) and the theory of thermal adaptation (Wu and Liu, 2000; Liu et al.,

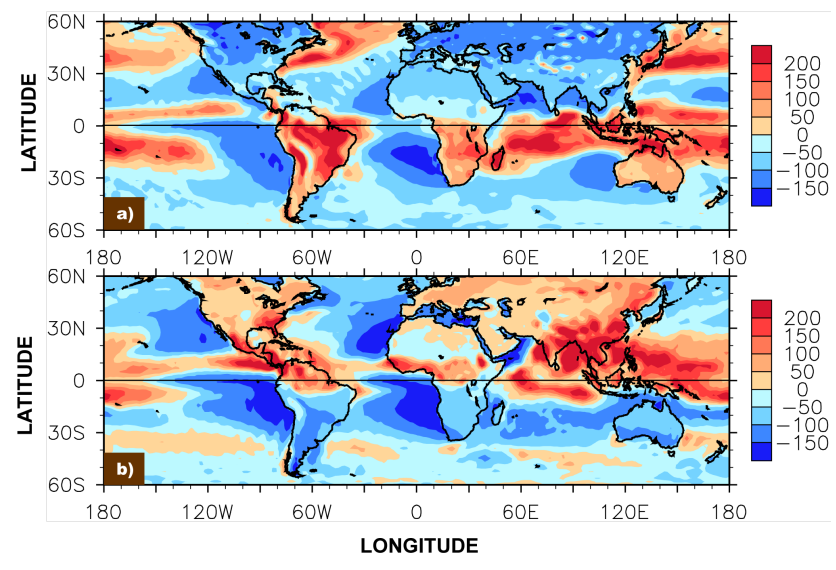

Fig. 1. Distributions of column-integrated total heating averaged over the period 1980-1997 for January (a) and July (b). Unit is $\mathrm{W} \mathrm{m}{ }^{-2}$.

2001), the atmosphere is expected to respond to summertime continental heating by the generation of cyclonic circulation in the lower troposphere and anticyclonic circulation in the upper troposphere (Fig. 2a), whereas it responds to cooling over oceans by the generation of anticyclonic circulation near the surface and cyclonic circulation in the upper troposphere (Fig. 2b). Because in summertime the zonal flow and vorticity advection across the subtropics are weak, the quasi-steady state geostrophic vorticity equation,

$u \frac{\partial \zeta}{\partial x}+v \frac{\partial \zeta}{\partial y}=-\beta v-f \nabla \cdot \boldsymbol{V}$

can be simplified to

$0 \approx-\beta v-f \nabla \cdot \boldsymbol{V}$.

Under the first-order approximation $0 \approx \nabla \cdot V+\frac{\partial w}{\partial z}$, Eq. (3) can be rewritten as

$\frac{\partial w}{\partial z} \approx \frac{\beta}{f} v$.

By assuming a characteristic height $H$ and a normal mode distribution of $w$ with height, we have

$w \propto-H^{2} \frac{\partial^{2} w}{\partial z^{2}} \propto-\frac{\beta H^{2}}{f} \cdot \frac{\partial v}{\partial z}$.

According to Eq. (3), on the eastern side of the heating region and the western side of the cooling region, the negative advection of planetary vorticity brought about by poleward flow in the lower troposphere should be balanced by in situ positive vorticity generated in response to horizontal convergence, while the positive advection of planetary vorticity brought about by equatorward flow in the upper troposphere should be balanced by in situ negative vorticity generated in response to horizontal divergence. Under the constraint of fluid continuity, ascending motion should develop on the 
a)

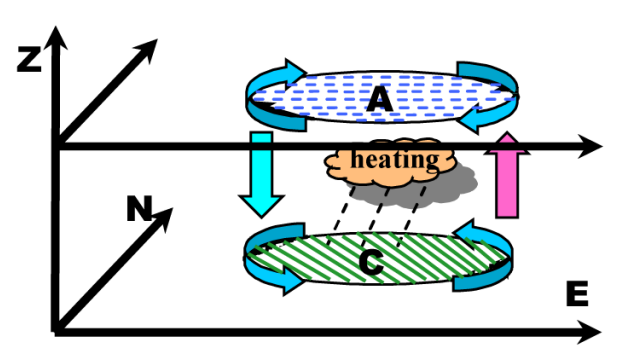

b)

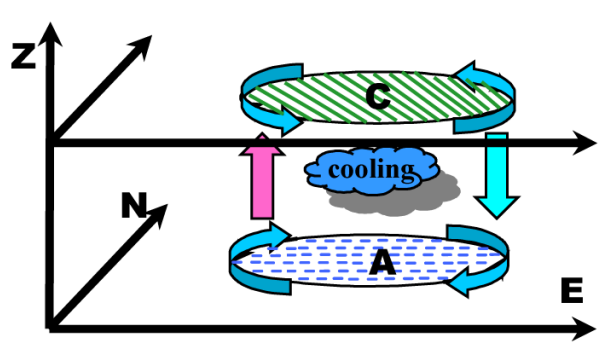

Fig. 2. Schematic diagram showing atmospheric adaptation on the rotating earth to external heating in the summertime subtropics: (a) Diabatic heating generates cyclonic circulation (C) near the surface and anticyclone circulation (A) in the upper troposphere, with air ascent developing over the eastern part of the circulation and descent over the western part. (b) Diabatic cooling generates anticyclonic circulation near the surface and cyclone circulation in the upper troposphere, with air descent developing over the eastern part of the circulation and ascent over the western part.

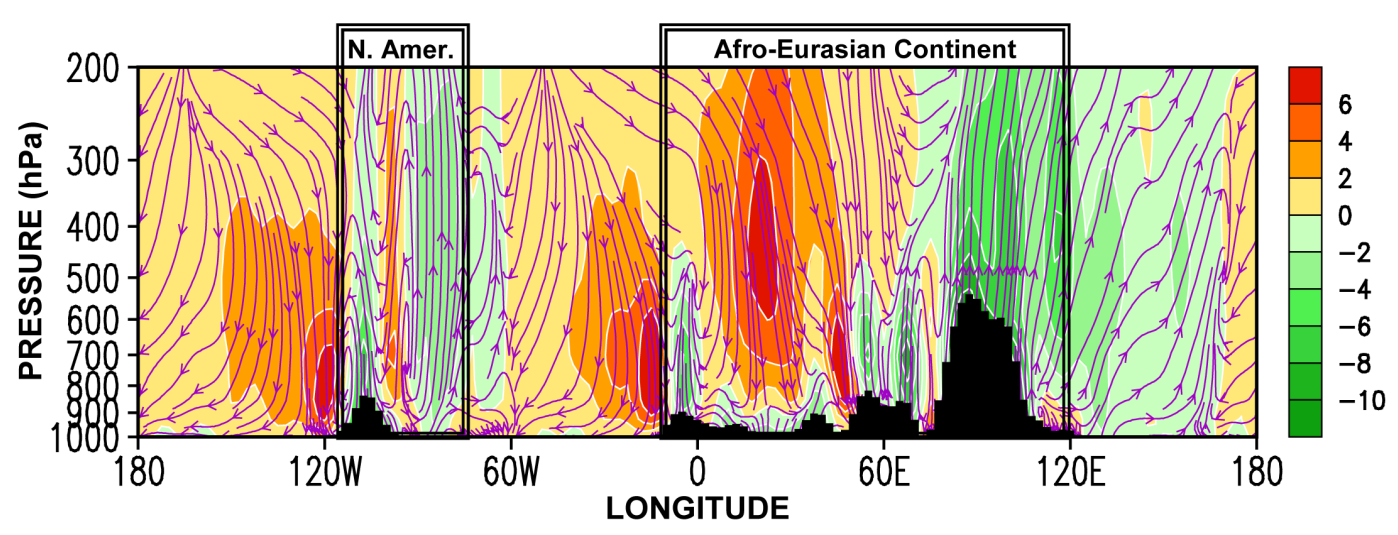

Fig. 3. July mean vertical cross-section of subtropical circulation along $30^{\circ} \mathrm{N}$ (vertical velocity has been amplified by a factor of 100 ). The boxes indicate the locations of the North American and Afro-Eurasian continents. Black shading indicates orography, and color shading indicates the intensity of the vertical p-velocity $\omega$ (interval, $2 \mathrm{~Pa} \mathrm{~s}^{-1}$ ), as shown in the color scale to the right.

eastern side of the heating region over continent and the western side of the cooling region over ocean. In other words, the ascending motion over the eastern continent and the western ocean is forced by the negative vertical shear of the in situ meridional wind, as described in Eq. (4). In contrast, the vertical shear of the in situ meridional wind is positive on the western side of the heating region over continent and the eastern side of the cooling region over ocean. According to Eq. (4), descending motion should develop in these regions, as shown schematically in Fig. 2.

Figure 3 shows the July mean vertical cross-section of streamline $(u, w)$ along $30^{\circ} \mathrm{N}$, in which the vertical velocity has been amplified by a factor of 100 . The general features in the cross-section show a good fit with the thermal adaptation described above: ascending motions develop over the eastern parts of the North American and Eurasian continents and over the western parts of the North Pacific and North Atlantic, whereas descending motions develop over the western parts of the North American and Eurasian continents and over the eastern parts of North Pacific and North Atlantic.

\section{Local-scale sea breeze and heating pattern across the summertime subtropics}

The color shading in Fig. 3 shows the magnitude of the vertical p-velocity $\omega$ along $30^{\circ} \mathrm{N}$. Although ascending motions develop over both eastern parts of continents and western parts of oceans, the rising over land is apparently stronger than over the sea to the east. Similarly, the descending motion over the eastern ocean is much stronger than that over the neighboring land to the east. This feature can also be detected from the distributions of heating/cooling in the summertime subtropics (see Fig. 1): atmospheric heating over the eastern subtropical continents is always stronger than that over the neighboring ocean to the east, and atmospheric cooling over the eastern subtropical oceans is always the strongest along the subtropical zones.

To examine the origin of the above pattern, Fig. 4 shows the velocity potential $\chi$ and the corresponding divergent wind component at $1000 \mathrm{hPa}$. In the northern extra-tropics in January (Fig. 4a), the velocity potential is generally low 


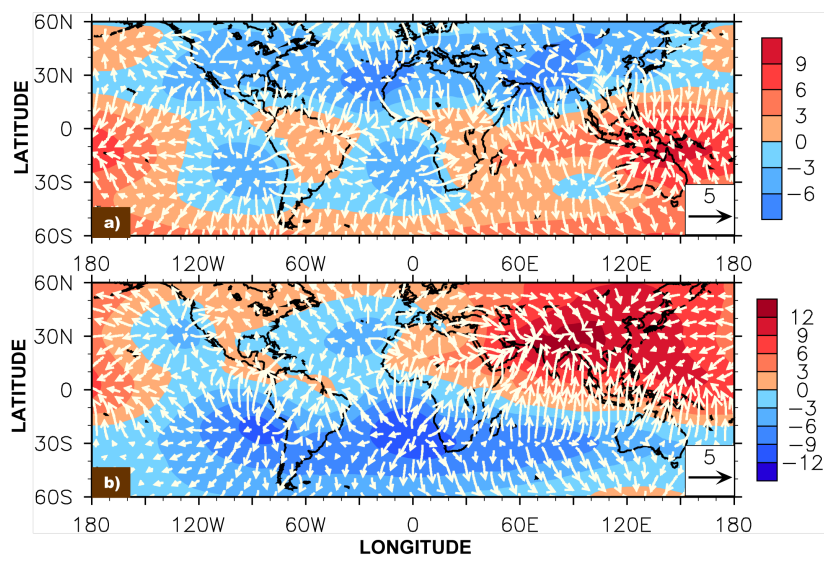

Fig. 4. Distributions of the monthly mean velocity potential (shading, unit is $10^{-6} \mathrm{~m}^{2} \mathrm{~s}^{-1}$ ) and divergent wind (arrows, $\mathrm{m} \mathrm{s}^{-1}$ ) at $1000 \mathrm{hPa}$ in January (a) and July (b).

over land and high over ocean. Air flows from land to ocean, occurring as a land-breeze except over the eastern subtropical North Atlantic. In July (Fig. 4b) in the Northern Hemisphere, the velocity potential is low over oceans and high over continents. During this month, a strong sea breeze dominates coastal regions in the summertime extra-tropics. This seasonal contrast in the occurrences of land and sea breezes is also evident in the Southern Hemisphere, although not as prominent as that in the Northern Hemisphere.

In summary, summertime sea breezes along subtropical coastal regions form a localized circulation, with ascending motion over coastal land and descending motion over the adjacent coastal sea. When such a localized sea-breeze circulation is superimposed on the continental-scale circulation induced by the land-sea distribution (see Fig. 2), the ascending motion over the eastern continent is enhanced, while the ascending motion over the neighboring western ocean region, to the east of the continent, is suppressed to some extent. Similarly, the descending motion over the eastern ocean region is intensified, while the descending motion over the neighboring western continent is weakened. These findings explain the asymmetry in the observed distribution of vertical velocity (Fig. 3).

The distribution of vertical motion associated with continental-scale forcing and local sea breeze is closely related to in situ heating/cooling. Figure 5 shows various vertical heating profiles at different sites across the North American and Eurasian continents along $30^{\circ} \mathrm{N}$ in July. The locations of the selected sites are as follows: $\mathrm{LO}\left(122^{\circ} \mathrm{W}, 30^{\circ} \mathrm{N}\right)$, SE $\left(108^{\circ} \mathrm{W}, 30^{\circ} \mathrm{N}\right), \mathrm{CO}\left(80^{\circ} \mathrm{W}, 30^{\circ} \mathrm{N}\right)$, and $\mathrm{D}\left(60^{\circ} \mathrm{W}\right.$, $30^{\circ} \mathrm{N}$ ) for North America (Fig. 5a), and $\mathrm{LO}\left(24^{\circ} \mathrm{W}, 30^{\circ} \mathrm{N}\right)$, $\operatorname{SE}\left(0,30^{\circ} \mathrm{N}\right), \mathrm{CO}\left(120^{\circ} \mathrm{E}, 30^{\circ} \mathrm{N}\right)$, and $\mathrm{D}\left(145^{\circ} \mathrm{E}, 30^{\circ} \mathrm{N}\right)$ for Afro-Eurasia (Fig. 5b). These sites are located within different heating lobes (see Fig. 6b), and are representative of the heating characteristics of the surrounding areas. Site LO is located over the eastern ocean, where the column-integrated total heating is negative. The strong atmospheric sinking in the region (Fig. 3) indicates strong atmospheric cooling. The characteristics of heating in this region can be described as follows:

At Site LO, $\left\{\begin{array}{l}\int_{0}^{p_{0}} Q \frac{d p}{g}<0 ; \\ \boldsymbol{V} \cdot \nabla \theta<0, \text { in the free atmosphere. }\end{array}\right.$

In these LO regions, condensation heating is very weak, and surface sensible heating is negligible (Fig. 5, left-hand panels). These regions are located to the east of surface oceanic anticyclones that are produced by summertime atmospheric cooling over oceans, as discussed in Sect. 3, and are marked by strong equatorward surface wind-drag. Because the SST in these regions is cold due to the upwelling of cold sea water in association with surface equatorward flow, and because the atmosphere is subject to adiabatic warming due to strong descent, atmospheric stratification in the boundary layer is stable, and low-level stratus cloud is formed persistently (data not shown). The total heating profile is therefore dominated by long-wave radiative cooling, with a maximum cooling of about $6^{\circ} \mathrm{C}$ per day at about $900 \mathrm{hPa}$, close to the top of the low-level stratus cloud.

Site SE is located over the western continent, where column-integrated total heating is positive (Fig. 1b). Weak atmospheric sinking in this region (Fig. 3) indicates cooling in the free atmosphere. The characteristics of heating in this region can be described as follows:

At Site SE, $\left\{\begin{array}{l}\int_{0}^{p_{0}} Q \frac{d p}{g}>0 \\ \boldsymbol{V} \cdot \nabla \theta<0, \text { in the free atmosphere. }\end{array}\right.$

Therefore, atmospheric heating should be confined to the boundary layer, and the total heating profile in this region follows the diffusive sensible heating profile (Fig. 5, panels located second from left).

Site CO is located over the eastern continent, where column-integrated total heating is strongly positive. The atmosphere ascends intensely in this region (Fig. 3), indicating strong heating in the free atmosphere. The characteristics of heating in this region can be described as follows:

$$
\text { At Site CO, }\left\{\begin{array}{l}
\int_{0}^{p_{0}} Q \frac{d p}{g}>0 ; \\
\boldsymbol{V} \cdot \nabla \theta>0, \text { in the free atmosphere. }
\end{array}\right.
$$

Therefore, the total heating profile in this region is strongly consistent with the profile of deep condensation heating (Fig. 5, panels located third from left).

Site D is located over the western ocean, where the column-integrated total heating is negative (Fig. 1b). The atmosphere also ascends in this region, albeit much more weakly than at Site CO (Fig. 3). This finding indicates the existence of condensation heating in the free atmosphere. The 


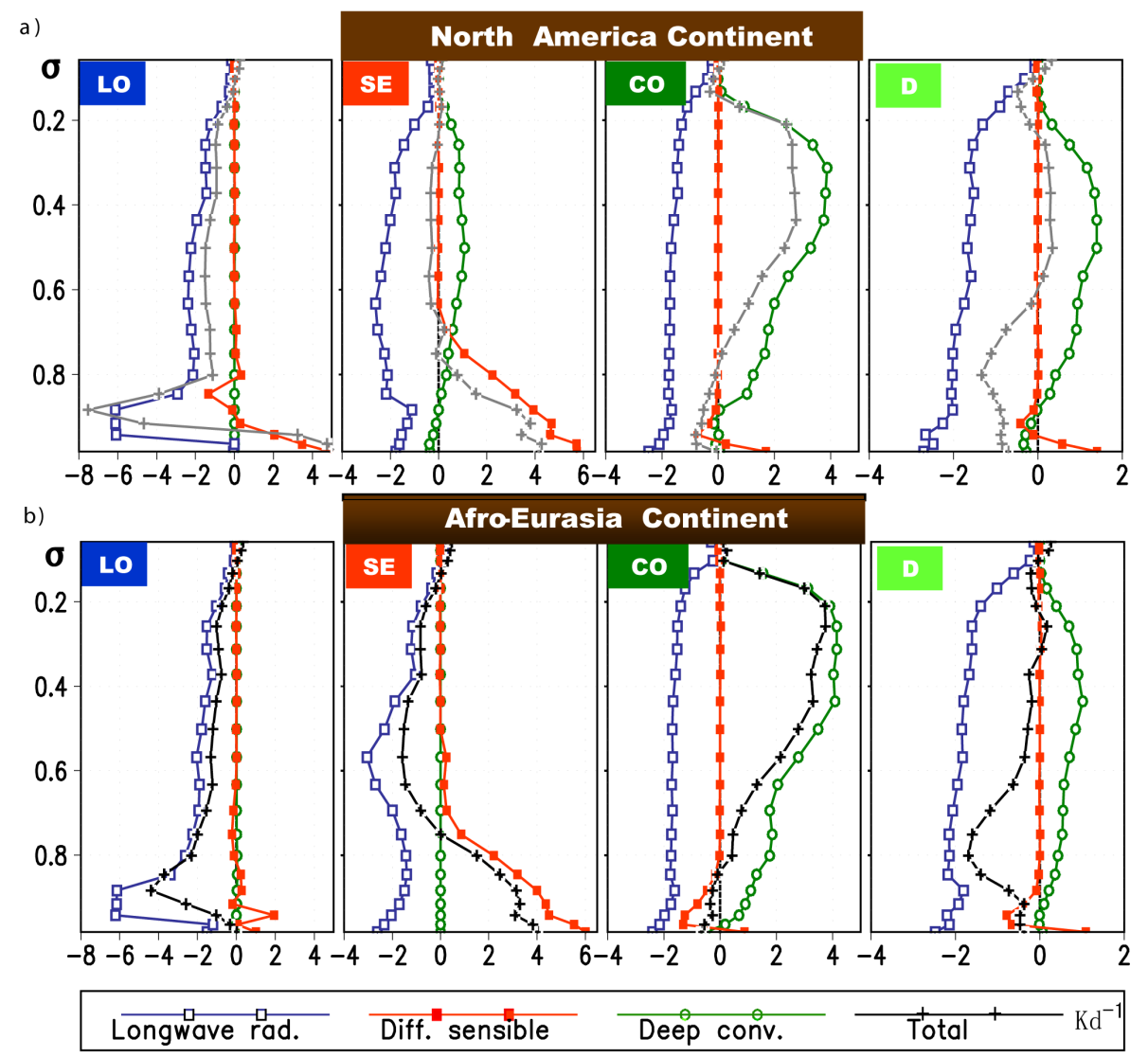

Fig. 5. July mean vertical heating profiles in sigma $(\sigma)$ coordinates for locations LO, SE, CO, and D (see Fig. 6b for locations) across (a) North America and adjacent oceans, and (b) the Afro-Eurasian Continent and adjacent oceans (after Wu and Liu, 2003; Liu et al., 2004). The lines with open squares, filled squares, open circles, and "plus" signs represent long-wave radiative cooling (LO), diffusive sensible heating (SE), deep convective condensation heating (CO), and total heating, respectively. Unit is $\mathrm{Kd}^{-1}$.

characteristics of heating in this region can be described as follows:

$$
\text { At Site D, }\left\{\begin{array}{l}
\int_{0}^{p_{0}} Q \frac{d p}{g}<0 \\
\boldsymbol{V} \cdot \nabla \theta>0, \text { in the free atmosphere. }
\end{array}\right.
$$

Therefore, the total heating profile in this region is determined by two dominant heating profiles: long-wave radiative cooling (LO) and condensation heating (CO) (Fig. 5, righthand panels).

When these dominant heating features are linked side by side, it is then possible to explain the formation of the specific summertime heating pattern identified by Wu and Liu (2003, Figs. $3 \mathrm{~b}$ and $4 \mathrm{~b}$ ) and Liu et al. (2004). As demonstrated in Figs. $6 \mathrm{~b}$ and $7 \mathrm{~b}$, in both hemispheres the dominant summertime subtropical heating, from west to east across each continent and adjacent oceans, is well organized into a specific pattern: long-wave radiative cooling (LO) to the west of the continent, surface sensible heating (SE) in the western part of the continent, deep condensation heating $(\mathrm{CO})$ in the eastern part, and double dominant heating $(\mathrm{D}=\mathrm{LO}+\mathrm{CO})$ to the east.
Consequently, the summertime subtropical diabatic heating shows a mosaic of the LOSECOD quadruplet heating pattern.

The summertime zonal flow along the subtropics is weak, and the atmospheric adaptation to external heating is manifest as the following Sverdrup vorticity balance (Wu and Liu, 2000; Liu et al., 2001) or, to distinguish this equation from the oceanic Sverdrup balance, thermal vorticity balance (TVB):

$\beta v \approx \theta_{z}^{-1}(f+\zeta) \frac{\partial Q}{\partial z}$.

This equation states that the generation of vorticity due to summertime diabatic heating in the subtropics is balanced mainly by the meridional transfer of planetary vorticity. Thus, increased heating with height produces poleward flow, whereas decreased heating with height generates equatorward flow. According to the vertical distributions of heating profiles shown in Fig. 5, the total heating profiles over the eastern ocean and western continent decrease with height in the lower troposphere, and increase with height in the 

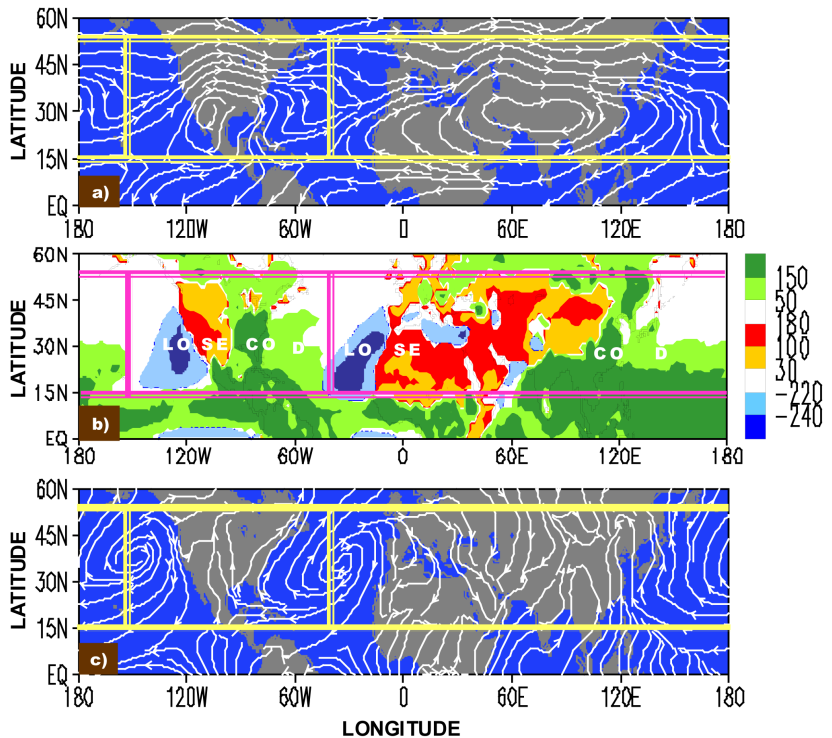

Fig. 6. Distributions of July mean quadruplet LOSECOD dominant heating (b, unit is $\mathrm{W} \mathrm{m}^{-2}$; adopted from Fig. $3 \mathrm{~b}$ of $\mathrm{Wu}$ and Liu, 2003), and circulation at $200 \mathrm{hPa}$ (a) and $1000 \mathrm{hPa}$ (c). Each grid along the subtropics has one continent in the center and is bounded by the longitudes at which the centers of sea-surface anticyclones are located. The abbreviations LO, SE, CO, and D in panel (b) indicate the geographic locations at which the vertical profiles of heating are plotted in Fig. 5.

upper troposphere. Therefore, in boreal summer, strong nearsurface northerlies and upper-layer southerlies are expected to be generated over the eastern ocean and western continent. Over the eastern continent and western ocean areas, the total heating increases with increasing height in the lower troposphere, and shows a rapid decrease with height in the upper troposphere. Therefore, near-surface southerlies and strong upper-layer northerlies are expected to be generated over these areas. The same patterns apply to austral summer; consequently, anticyclonic circulation appears in the upper troposphere over continents, with tilting troughs over oceans (Figs. 6a and 7a). Near the surface, cyclone circulation is intensified over land, while anticyclone circulation is enhanced over ocean, especially over the eastern ocean (Figs. 6c and 7c).

\section{Local positive feedback mechanism and development of dry and wet climate}

In nature, the atmospheric heating source is not just the cause of atmospheric motion: it is also a consequence of the general circulation (Eady, 1950). Atmospheric ascent over the eastern continent and descent over its western part, as induced by continental-scale and sea-breeze coastal-scale forcing, favor the occurrence of a wet climate event in the east and dry climate event in the west. However, the formation of
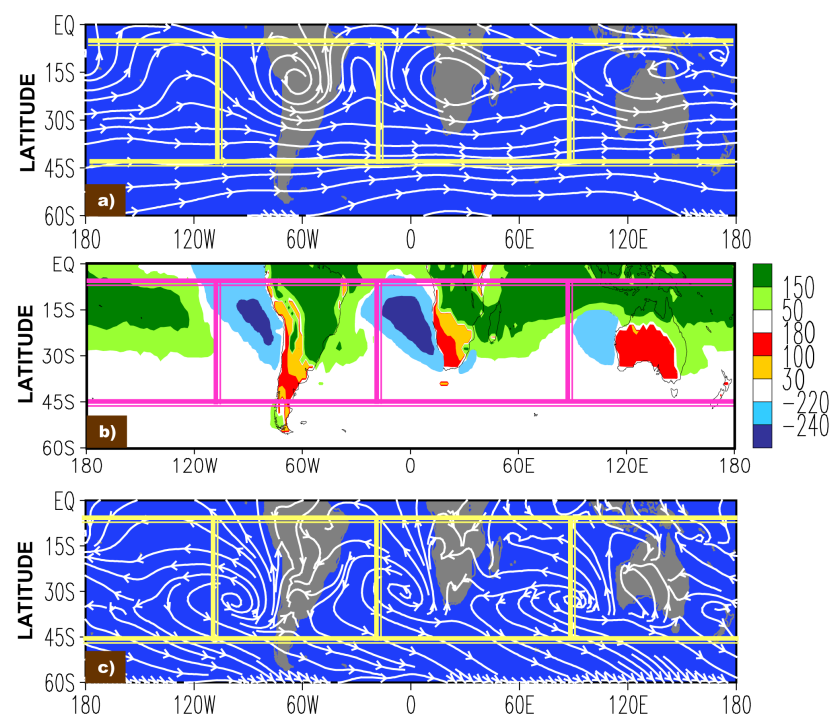

Fig. 7. Distributions of January mean quadruplet LOSECOD dominant heating (b, unit is $\mathrm{W} \mathrm{m}^{-2}$; adopted from Fig. $4 \mathrm{~b}$ of Wu and Liu, 2003), and circulation at $200 \mathrm{hPa}$ (a) and $1000 \mathrm{hPa}$ (c). Each grid along the subtropics has one continent in the center and is bounded by the longitudes at which the centers of sea-surface anticyclones are located.

desert and monsoon requires the persistence of such events, requiring in turn a positive feedback mechanism.

Over the eastern ocean and western continent, the increase in radiative cooling with height in the LO region and the decrease in sensible heating with height in the SE region (Fig. 5) generate negative vorticity in the lower troposphere. In the absence of zonal advection and at a steady state, this negative vorticity generation is balanced mainly by positive planetary vorticity advection from higher latitudes, resulting in strong meridional wind from higher latitudes (Eq. 9). As discussed above, over the eastern parts of oceans, this strong equatorward meridional wind causes strong ocean upwelling and cold SST. The wind also enhances in situ stable stratification and sustains low-level stratus cloud and long-wave radiative cooling at the cloud top, thereby leading to the further generation of negative vorticity. Accordingly, a positive feedback is established between longwave radiative cooling and negative vorticity forcing.

Over the western continent, this meridional flow brings cold and dry air from high latitudes into the area, resulting in an increased difference in temperature and moisture between the land surface and overlying air, and enhancing the surface sensible heat flux and evaporation. Strong negative vorticity is continuously generated and the soil becomes drier. Thus, the meridional transfer of heat and vorticity results in a positive feedback between negative vorticity generation and surface sensible heat transfer, and the soil becomes progressively drier. This positive feedback process continues until it is balanced by surface friction (which is ignored in 

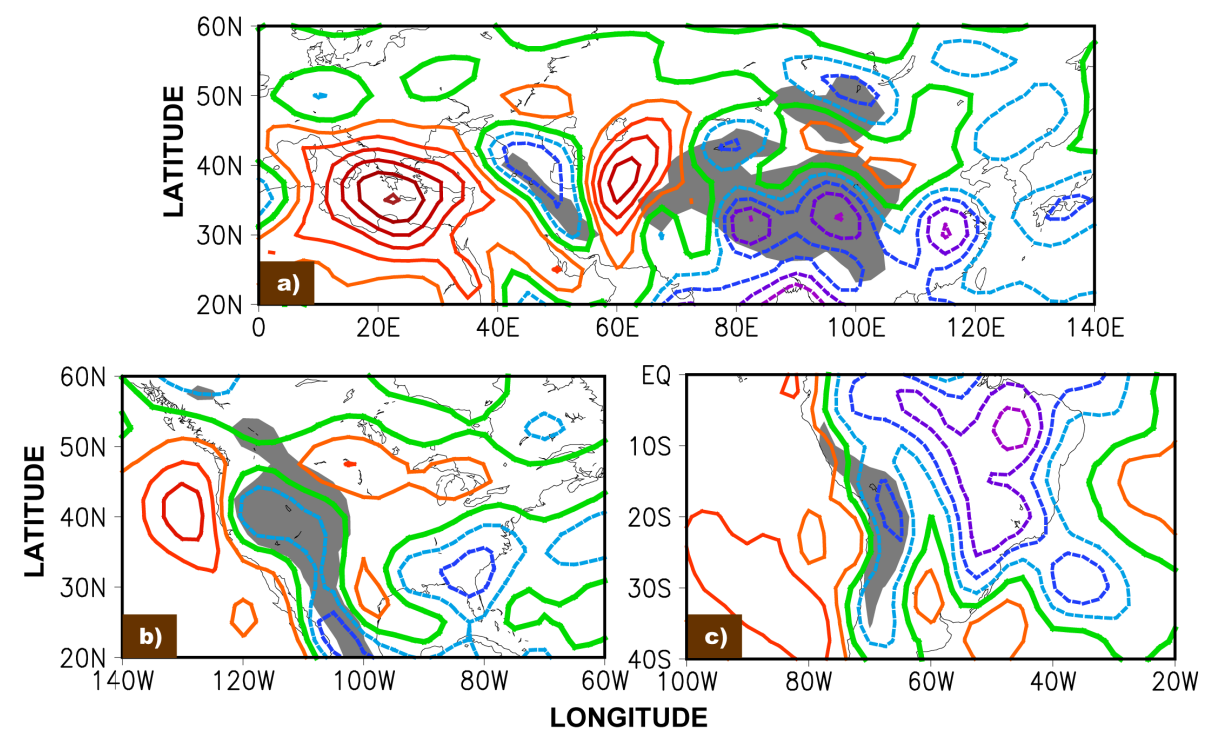

Fig. 8. Distributions of "vertical velocity" $\omega$ at $500 \mathrm{hPa}$ over (a) the Afro-Eurasia Continent in July, (b) North America in July, and (c) South America in January. Contour interval is $2 \times 10^{-2} \mathrm{~Pa} \mathrm{~s}^{-1}$. Solid and dashed lines indicate air descent and ascent, respectively; the green line denotes the zero isoline, and gray shading indicates topography above $1500 \mathrm{~m}$.

Eq. 9). Dry, arid, and even desert-like climates are formed over the western continent, as shown in Figs. 6 and 7 (and also in Fig. 12, which is discussed later in the text).

Over the eastern continent and adjacent western ocean areas, the increase in condensation heating with height (Fig. 5) generates positive vorticity. In the absence of zonal advection and at a steady state, this positive vorticity generation is balanced mainly by negative planetary vorticity advection from lower latitudes, resulting in strong meridional wind from lower latitudes (Eq. 9). This poleward meridional flow brings warm and moist air into the region, and creates convective instability, enabling convection to develop. Condensation heating is then sustained, and positive vorticity continues to be generated. Thus, the meridional transfer of heat and vorticity generates a positive feedback between positive vorticity generation and condensation heating, until equilibrated by frictional dissipation. Wet and even monsoon-like climates are formed over the eastern continent, as shown in Figs. 6, 7, and 12.

\section{Regional-scale orographic forcing and formation of monsoon and desert}

Figures 1 and 3 reveal significant differences between East Asia and North and South America in the intensity of vertical motion and the horizontal extent of convective condensation heating. The ascending air over East Asia covers the area east of $75^{\circ} \mathrm{E}$, and becomes intense east of $90^{\circ} \mathrm{E}$ (Fig. 3). In contrast, the ascent of air over North and South America is relatively weak, and the regions of ascending air produced by mountain forcing and continental forcing are separated by descending air.

Such a phenomenon can be seen more clearly from the horizontal distribution of vertical velocity at $500 \mathrm{hPa}$, as shown in Fig. 8. Within the subtropics in Eurasia during July (Fig. 8a), atmospheric descent dominates the western part of the continent except over the Iran High, where orographyforced rising occurs. The centers of strong descent near $20^{\circ} \mathrm{E}$ and $60^{\circ} \mathrm{E}$ correspond to a Mediterranean-type persistent dry summertime climate and the Kyzylkum Desert, respectively; the strong ascent dominates the vast eastern continent from $75^{\circ} \mathrm{E}$ eastwards. Intense rising centers of greater than $-8 \times 10^{-2} \mathrm{~Pa} \mathrm{~s}^{-1}$ over the TP and East China are linked together. In contrast, the two rising centers over North America (Fig. 8b) are separated by a region of descent: one ascending center of $-4 \times 10^{-2} \mathrm{~Pa} \mathrm{~s}^{-1}$ is located over North Florida, and another center with similar intensity is located over the Rocky Mountains.

Similar features are observed in South America. Within the subtropics in South America during January (Fig. 8c), one ascending center is located over east Brazil, and another over the Andes, separated by descent over central South America. Furthermore, because the dominant heating over the eastern continent is convective condensation heating (Fig. 5), the horizontal extent of diabatic heating in these areas is consistent with convective condensation heating induced by monsoon or monsoon-like rainfall. As shown in Fig. 1, the heating area of $>100 \mathrm{~W} \mathrm{~m}^{-2}$ over East Asia extends northeastward to Northeast China. In contrast, comparable areas in other continents are confined to subtropical regions. 

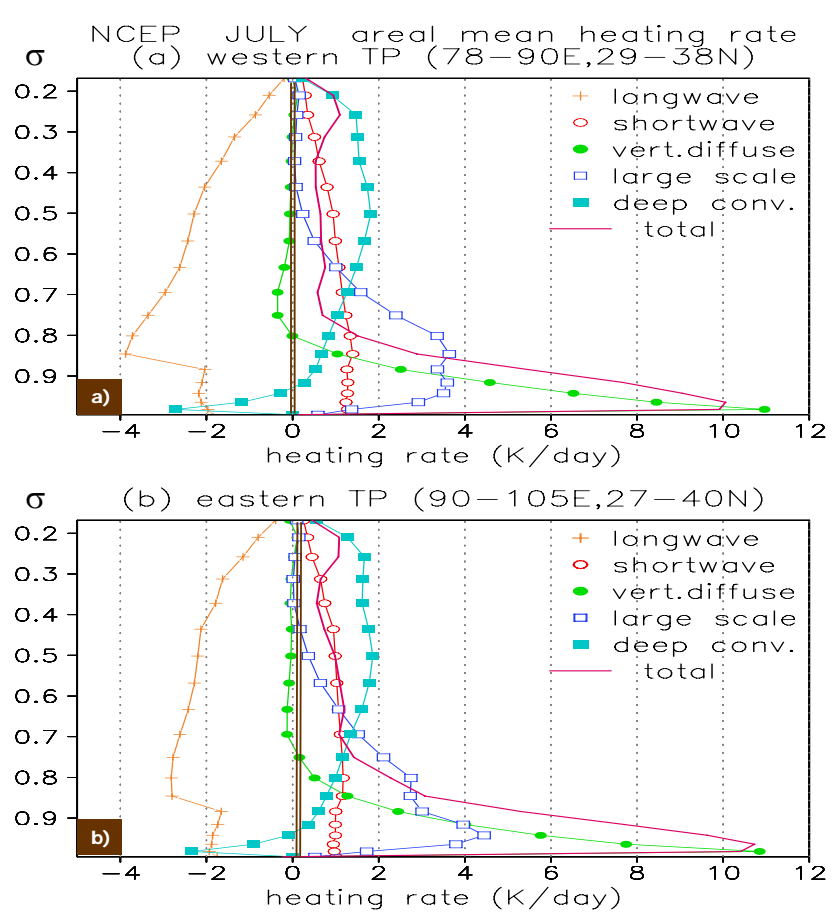

Fig. 9. July mean vertical profiles in $\sigma$-coordinate of various heatings over (a) the western Tibetan Plateau $\left(78-90^{\circ} \mathrm{E}, 29-38^{\circ} \mathrm{N}\right)$ and (b) the eastern Tibetan Plateau $\left(90-105^{\circ}\right.$ E, $\left.27-40^{\circ} \mathrm{N}\right)$. Lines with "plus" signs, open circles, filled circles, open squares, and filled squares represent long-wave radiative cooling, short-wave radiative heating, vertical diffusive heating, large-scale condensation heating, and convective condensation heating, respectively. Red solid lines indicate total heating. Unit is $\mathrm{Kd}^{-1}$.

The above findings indicate that the East Asian monsoon is the strongest subtropical monsoon in the world, as also reported in many previous studies (e.g., Tao and Chen, 1987; Yanai and Li, 1994; Yanai and Wu, 2006). Other studies (Yeh et al., 1957; Wu et al., 1997b) have suggested that the strength of the East Asian monsoon is due to the existence of the TP. To further investigate the formation of the strong East Asian monsoon, we perform idealized numerical experiments to demonstrate how the location of the plateau affects the intensity and extent of desert and the East Asian monsoon.

Figure 9 shows the July mean vertical heating profiles averaged over the western part of the TP $\left(78-90^{\circ} \mathrm{E}, 29-\right.$ $\left.38^{\circ} \mathrm{N}\right)$ and the eastern part $\left(90-105^{\circ} \mathrm{E}, 27-40^{\circ} \mathrm{N}\right)$. The magnitude of large-scale near-surface condensation heating over the eastern part of the plateau $\left(4.5 \mathrm{~K} \mathrm{~d}^{-1}\right)$ is slightly higher than that over the western part $\left(3.5 \mathrm{~K} \mathrm{~d}^{-1}\right)$, and the magnitude of longwave radiative cooling over the western part is slightly stronger than that over the eastern part; however, all other types of heating are similar over the two parts. The profile of total heating is positive throughout the entire troposphere, with a striking maximum of about $10 \mathrm{~K} \mathrm{~d}^{-1}$ near the surface. The atmospheric adaptation to such uplift heat- ing is expected to generate strong surface cyclonic circulation and upper-layer anticyclonic circulation. The superimposition of these orography-induced local circulations on continental-scale circulations is likely to affect the climate of the surrounding area.

To verify the above hypothesis, we performed idealized aqua-planet numerical experiments based on the GOALS SAMIL GCM, which is described in Sect. 2. An idealized Afro-Eurasian continent, as outlined by the thick dashed lines in Figs. 10 and 11, is embedded into the aqua planet. The use of these types of aqua-planet sensitivity experiments can simplify the complicated dynamical diagnosis and accentuate the physics under consideration. Furthermore, because the outcomes of such experiments can be linked to the corresponding theoretical understanding, ensemble evaluations are generally not required. The SST and sea ice are the zonal averaged AMIP products. The seasonal variable land-surface albedo and solar radiation are prescribed using the zonal averaged products of the long-term integration of the GOALS SAMIL GCM. The surface temperature over land is forecasted in the model. The model is integrated for 12 years, and the outcomes from the last 10 years are extracted for the current analysis.

We performed three experiments, as briefly described in Table 1. The first experiment (NOMT) possesses only the land-sea distribution, mimicking the existence of the AfroEurasian Continent. In the second experiment (MT90), an idealized ellipsoidal "TP" is placed on the continent. Its maximum height is $5000 \mathrm{~m}$, and its center is located at $87.5^{\circ} \mathrm{E}$, $32.5^{\circ} \mathrm{N}$, mimicking the actual plateau. The third experiment (MT60) is the same as MT90, except that the center of the "TP" is moved to $60.0^{\circ} \mathrm{E}, 32.5^{\circ} \mathrm{N}$, about $30^{\circ}$ to the west of its actual location.

Figure 10 shows the simulated July mean precipitation and circulation at $925 \mathrm{hPa}$. The area with a July-January difference in wind direction of $>120^{\circ}$ is marked by the thick red lines in Fig. 10a-c. This area, together with the area with a July mean rainfall of more than $6 \mathrm{~mm} \mathrm{~d}^{-1}$, indicates the occurrence of monsoon. In the no-mountain experiment (NOMT; Fig. 10a) along the subtropical area, the summertime heating over land and cooling over ocean (figures not shown, refer to Fig. 1) generate near-surface cyclonic circulation over continent and anticyclonic circulation over ocean. An intense inter-tropical convergence zone (ITCZ) appears along the equator in the Pacific, and remarkable tropical monsoon rainfall occurs over South Asia and the Indochina Peninsula; however, the model fails to represent the West Africa monsoon or the westerly along the western coast, as most of the features that contribute to these systems (e.g., the shape of coastline, topography, and the cold tongue in the eastern equatorial Atlantic) are not included in the idealized model. Nevertheless, weak East Asian monsoon rainfall of $6-8 \mathrm{~mm} \mathrm{~d}^{-1}$ is observed over the southeastern corner of the Afro-Eurasian continent. 
Table 1. Design of the aqua-planet sensitivity experiments using an idealized Afro-Eurasian continent.

\begin{tabular}{ccccl}
\hline & Center of mountain & Mountain shape & Mountain height & Purpose of the experiment \\
\hline NOMT & $/$ & $/$ & $\begin{array}{l}\text { Assess how circulation and rainfall re- } \\
\text { spond to the land-sea distribution }\end{array}$ \\
MT90 $\left(87.5^{\circ} \mathrm{E}, 32.5^{\circ} \mathrm{N}\right)$ & Ellipsoid & $5 \mathrm{~km}$ & $\begin{array}{l}\text { Assess how circulation and rainfall re- } \\
\text { spond to a mountain located on the east } \\
\text { of the continent }\end{array}$ \\
MT60 & $\begin{array}{l}\left(60.0^{\circ} \mathrm{E}, 32.5^{\circ} \mathrm{N}\right) \\
\text { Assess how circulation and rainfall re- } \\
\text { spond to a mountain located on the west } \\
\text { of the continent }\end{array}$ \\
\hline
\end{tabular}

In the MT60 experiment, in which the TP is superimposed over the western central continent (Fig. 10b), all the above features that appear in the NOMT run (e.g., continental cyclonic circulation, ITCZ, tropical monsoons, and the weak East Asian monsoon) are almost unchanged. However, another cyclonic circulation is produced surrounding the plateau, and significant rainfall $\left(>8 \mathrm{mmd}^{-1}\right)$ appears over the southeastern part of the plateau. This plateau-forced rainfall is geographically separated from the weak East Asian monsoon associated with continental-scale forcing.

In the MT90 experiment, in which the TP is located at its present-day position, with its center near $90^{\circ} \mathrm{E}$ (Fig. 10c), we still observe most of the features produced by continental forcing (see Fig. 10a). However, because the plateau has been moved eastward in this experiment, the cyclonic circulation surrounding the plateau, as shown in Fig. 10b, is also shifted eastward. Consequently, the rainfall forced by the plateau is merged into the rainfall band produced by continental-scale forcing, and they enhance each other. The East Asian monsoon now extends northward toward North China.

Figure 10d shows the differences between MT90 and NOMT in terms of daily rainfall and circulation at $925 \mathrm{hPa}$. The introduction of the "TP" intensifies not only the ITCZ, but also the East Asian monsoon rainfall, from the eastern part of the plateau to East China and Japan and Korea (shading), but results in reduced rainfall over South Asia (dotted contours). This occurs because the plateau generates a strong northerly to its west and southwest, but induces a strong southerly to its east and northeast, as shown by the difference flow (Fig. 10d).

To further illustrate the influence of the location of the TP on the formation of monsoon and desert, Fig. 11 shows the distributions of rainfall, meridional winds in the lower and upper troposphere, and a zonal vertical cross-section of subtropical circulation along $32.5^{\circ} \mathrm{N}$, as generated from experiments MT60 and MT90. In MT60 (Fig. 11a-c), there exist two anticyclonic circulations at $200 \mathrm{hPa}$ (Fig. 11a) and two related cyclonic circulations at $850 \mathrm{hPa}$ (Fig. 11b), corresponding to continental-scale forcing and plateau forcing, respectively. Subtropical rainfall possesses two centers: one over the eastern plateau and the other over East Asia. The vertical cross-section of circulation (Fig. 11c) shows two ascending branches over the Afro-Eurasian continent: one over the eastern plateau and another over East Asia, in good correspondence with the rainfall regions. Of note, a moderate airdescending region occurs below $300 \mathrm{hPa}$ in the troposphere, between the two ascending branches. This feature is similar to that observed along the subtropics over North America and South America (see Figs. 3, 8b, and 8c).

In contrast, experiment MT90 (Fig. 11d-f) produces only one anticyclonic circulation at $200 \mathrm{hPa}$ (Fig. 11d) and one cyclonic circulation at $850 \mathrm{hPa}$ (Fig. 11e), with relatively intense meridional winds and rainfall over the eastern part of the continent. In the vertical cross-section of circulation (Fig. 11f), there exists only one ascending region, spanning from the eastern plateau to Western Pacific, in good correspondence with the rainfall distribution over East Asia (see Fig. 11d and e) and in good agreement with the observed distribution of vertical motion in the area (Figs. 3 and 8a).

The results of the sensitivity experiments (Figs. 10 and 11) confirm our hypothesis that the location of the TP in the eastern part of the Afro-Eurasian continent results in an intensification of the monsoon climate to its east and the desert climate to its west. As shown in Fig. 12b, the area with more than $5 \mathrm{~mm} \mathrm{~d}^{-1}$ of July mean rainfall over East Asia has reached Northeast China, and the rainfall in South China exceeds $10 \mathrm{~mm} \mathrm{~d}^{-1}$. The East Asian monsoon is therefore the strongest subtropical monsoon in the world, in terms of both spatial coverage and intensity. To the west of the TP, the arid and desert areas with rainfall less than $2 \mathrm{~mm} \mathrm{~d}^{-1}$ extend from about $70^{\circ} \mathrm{E}$ westward to North Africa, forming the largest and driest desert area in the world. In contrast, the Rockies and Andes are located on the western continent. As shown in Fig. 12a and b, the monsoon-like rainfall over the eastern continent and the arid climate over the western continent in North and South America are not as pronounced as those over subtropical Asia. Because the mountain ranges in Australia and southern Africa are not as high as those in other continents, the monsoon and desert climates in these 

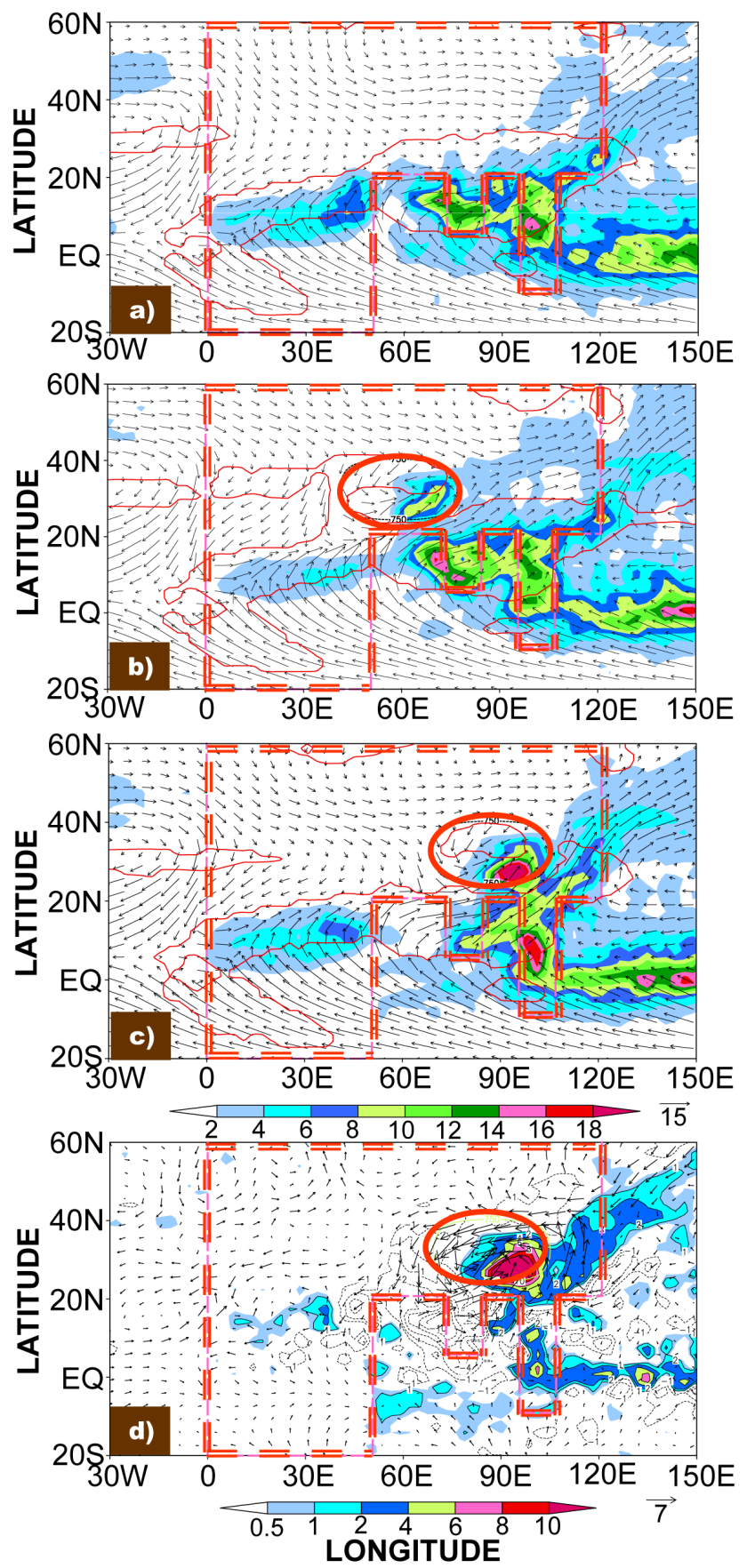

Fig. 10. Distributions of the 10 -year July mean rainfall (color shading, unit is $\mathrm{mm} \mathrm{d}^{-1}$ ) and wind at $925 \mathrm{hPa}$ (arrows, $\mathrm{ms}^{-1}$ ) in the experiments NOMT (a), MT60 (b), and MT90 (c). The differences between MT90 and NOMT are shown in (d). The red lines in $(\mathrm{a}-\mathrm{c})$ mark the area where the change in wind direction between July and January exceeds $120^{\circ}$. The thick dashed line denotes the idealized coastline, and the thick ellipse in (b-d) indicates land above $750 \mathrm{~m}$.

areas are somewhat atypical, although greater summer rainfall does occur over the eastern continent and a drier area occurs over the western continent.

\section{Summary and discussion}

The climate system is an open dissipative system that is subjected to various kinds of forcing. It behaves differently in response to different types of external forcing, and the response is complicated by feedback between external forcing and climate. In this study, we investigated three kinds of forcing (i.e., large-scale continental forcing, sea-breeze local forcing along coastal regions, and regional-scale plateau forcing) and demonstrated their contributions to the formation of monsoon and desert in the summertime subtropics from various perspectives. First, continental-scale heating over land and cooling over ocean produce near-surface cyclonic circulation over continent and anticyclonic circulation over ocean, and reversed circulations in the upper troposphere. Subject to the vorticity balance and continuity constrains, air ascends over the eastern continent and western ocean, and descends over the eastern ocean and western continent. Second, the sea breeze along coastal regions enhances the rising of air over the eastern continent to the west of the coast, and suppresses the rising over the western ocean to its east. The sea breeze also enhances the descent of air over the eastern ocean to the west of the western coast, and weakens the descent over the western continent to its east. Thus, as a consequence of the land-sea distribution, the dominant diabatic heating becomes well organized across each subtropical continent and its adjacent oceans in summer, and appears as a LOSECOD quadruplet-heating pattern.

Meridional transfer of heat and planetary vorticity give rise to positive feedback between vorticity generation and diabatic heating (longwave radiative cooling on the eastern parts of oceans, surface sensible heating on the western parts of continents, and condensation heating on the eastern parts of continents and western parts of oceans); the feedback continues until it is balanced by frictional dissipation. A warm, moist poleward flow develops in the lower troposphere over the eastern continent, resulting in abundant rainfall and a monsoon-like climate. On the western side of the continent, a cold, dry equatorward flow develops near the surface, soil moisture decreases, and an arid or even desert climate is developed. It should be noted that the divergent wind along the coastal line associated with sea-breeze forcing (as shown in Fig. $4 \mathrm{~b}$ ) is not independent of the rotational wind produced by continental forcing (Figs. 6 and 7); instead, they are related by formula (3), and both are formed in response to the contrasting heat capacities of land and ocean.

It is also worthwhile to compare the present results with those of previous studies. Chen et al. (2001) employed a linear quasi-geostrophic vorticity equation model to study the atmospheric response to a prescribed convective latent heating with a sinusoidal vertical profile. For a given constant basic flow of $U=0$ or $U<0$, the atmospheric response is simply a THB type, as presented in Eq. (9) and as obtained by Liu et al. (2001). When the basic flow becomes positive (i.e., $U=5$ or $10 \mathrm{~ms}^{-1}$ ), the response to the latent heating is wave-like, 

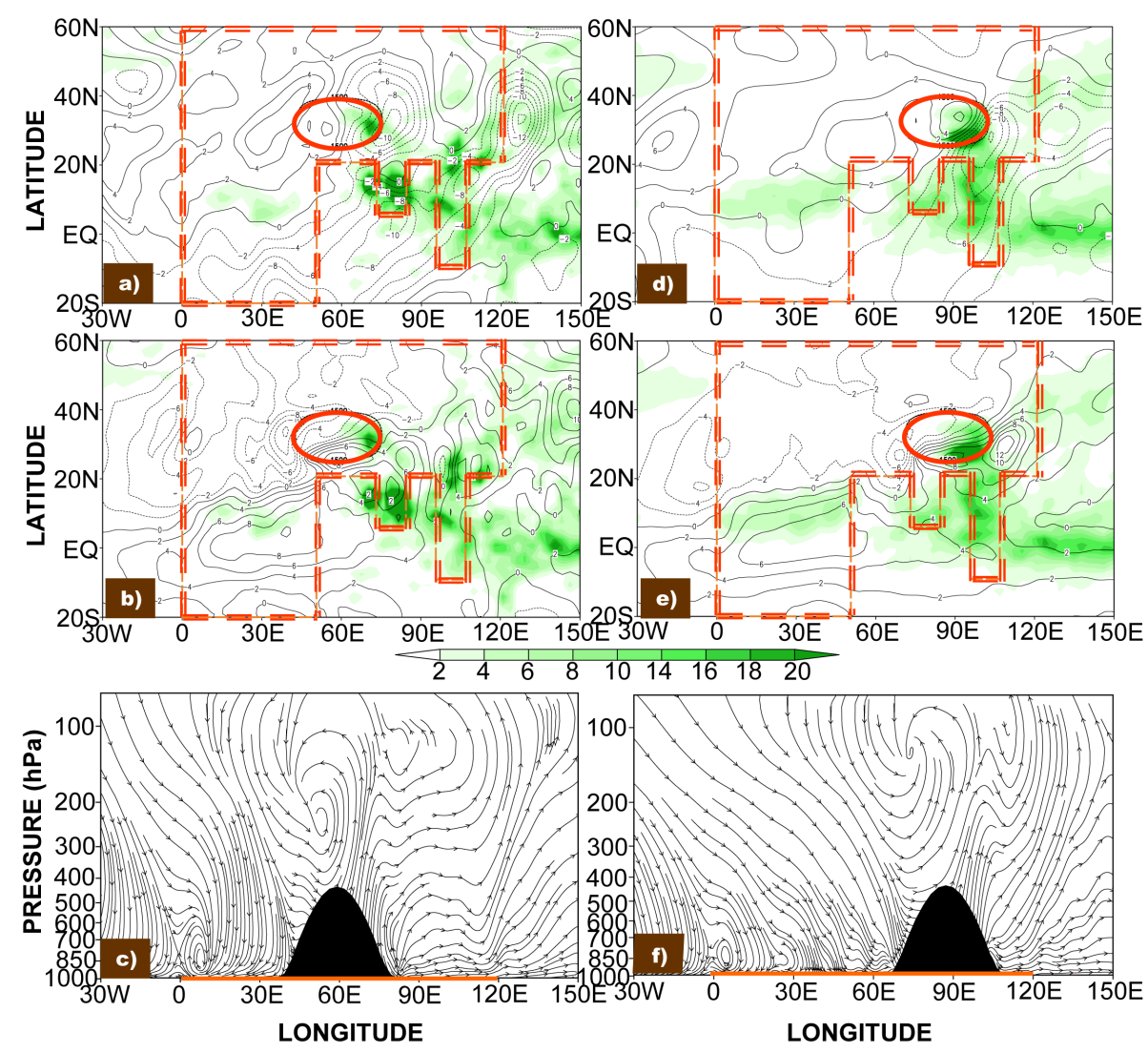

Fig. 11. Distributions of the 10-year July mean rainfall (a, b, d, and e; shading, unit is $\mathrm{mm} \mathrm{d}^{-1}$ ), meridional wind (solid contours (positive values) denote southerly wind, and dotted contours (negative values) denote northerly wind; interval is $2 \mathrm{~m} \mathrm{~s}^{-1}$ ) at $200 \mathrm{hPa}(\mathrm{a}$ and d) and $850 \mathrm{hPa}\left(\mathrm{b}\right.$ and e), and corresponding vertical cross-sections of circulation along $32.5^{\circ} \mathrm{N}$ (c and $\mathbf{f}$; black area represents the plateau) in the experiments MT60 (a-c) and MT90 (d-e). Thick dashed lines represent the idealized coastline, and ellipses indicate land with an elevation of $1500 \mathrm{~m}$.
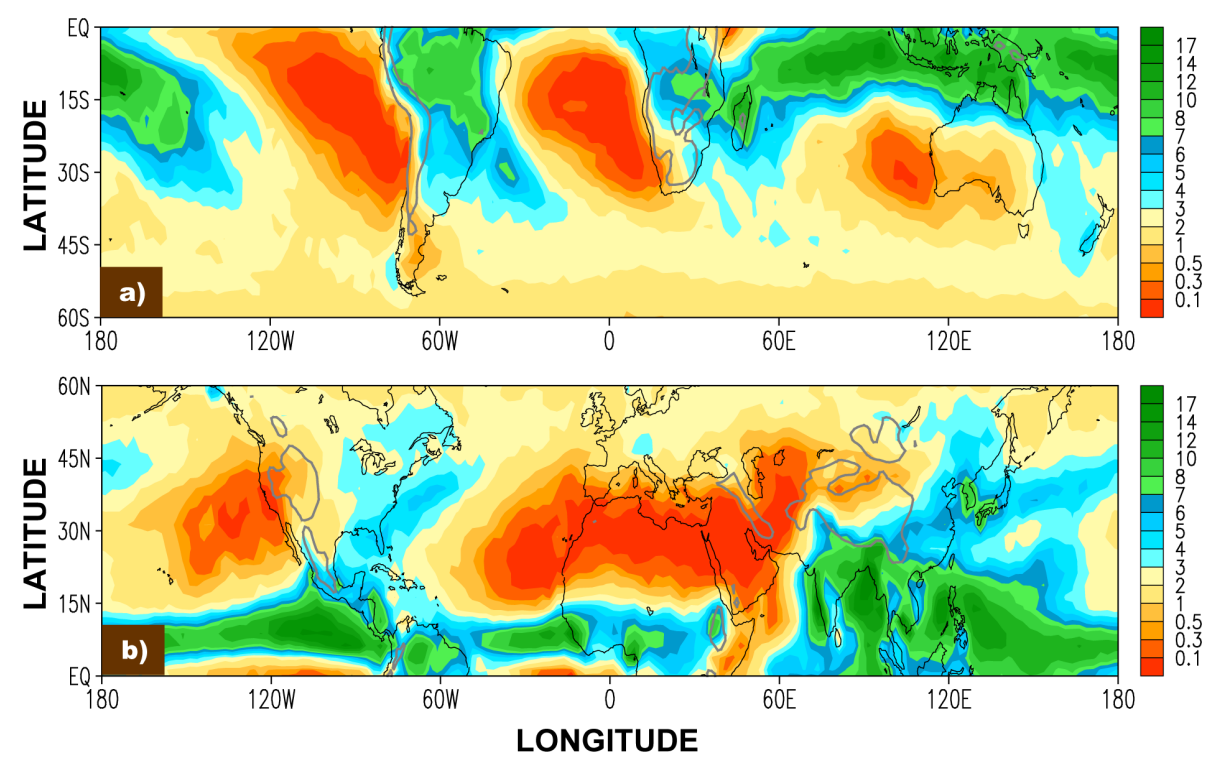

Fig. 12. Distributions of monthly mean rainfall ( $\mathrm{mm} \mathrm{d}^{-1}$ ) averaged over the period 1980-1997 for (a) January and (b) July, and grey lines indicate topography with an elevation of $1000 \mathrm{~m}$ in (a) and $1500 \mathrm{~m}$ in (b). 
and a weak surface anticyclone appears downstream. These findings were used to explain the formation of the summertime subtropical anticyclone over the ocean surface. However, the intensity of the downstream anticyclone is too weak to explain the summertime surface anticyclone. More importantly, the near-surface zonal flow is weak in the summertime subtropics, and the dynamics developed by Chen et al. (2001) show a better fit to middle and high latitudes, where westerlies are dominant, rather than the subtropics.

Rodwell and Hoskins (2001) recognized the " 'duality' between the monsoon condensation heating and the low-level subtropical circulation in the sense that either one would be very different without the other." The authors speculated that desert is formed as a remote Rossby-wave response to the west of subtropical summertime monsoon heating, with interaction with mid-latitude westerlies, resulting in a region of adiabatic descent. However, the strongest descent in response to forcing is close to the western part of the forcing (Fig. 8; see also Gill, 1980); in contrast, the observed deserts on the western parts of continents are located far from the monsoon region on the eastern continent. In fact, based on their standard model integration and trajectory analysis (Fig. 9 in Rodwell and Hoskins, 1996), all the trajectories along the subtropical westerly descend strongly over the Mediterranean Sea, and most of the trajectories that originated from the Asian monsoon region and along the tropical easterlies begin to ascend before reaching the Southern Hemisphere. There occurs limited interaction between the westward and eastward trajectories because the former travel above $300 \mathrm{hPa}$, whereas the latter travel below $400 \mathrm{hPa}$, despite their similar original heights. In fact, Figs. 6a and 8a show that the strong descent centers located over the Mediterranean and mid-Asia occur below the upper troposphere westerlies, in agreement with the trajectory analysis of Rodwell and Hoskins mentioned above. Figures 3, 8a, and 12 show that the strong descent and deserts over North Africa-Mediterranean and mid-Asia are closely related to the continental-scale forcing and the forcing of the Iran Plateau and the TP.

In terms of the third type of forcing, the uplifted heating of regional-scale plateau forcing in summer generates a pronounced Rossby-wave-type circulation with poleward flow and atmospheric ascent to the east, and equatorward flow and descent to the west of the plateau. The TP is located within the eastern Eurasian continent. Atmospheric circulation produced by the TP is in phase with that of continental-scale and sea-breeze forcing. The strongest monsoon and deserts are therefore formed over the African and Eurasian continents. In contrast, the Rockies and Andes are located over the western parts of continents; although the descending motion over the oceanic regions to the west of North and South America are strongly intensified, the ascending regions over the continents due to orographic forcing are separated from those due to continental forcing. The desert and monsoon climates over these continents are not as strong as those over the Eurasian
Continent.

In summary, the observed summertime subtropical climate pattern, with abundant rainfall or monsoon on the east of the continent and aridity or desert on the west, is formed in response to the combined effects of continental-scale forcing, local-scale coastal sea-breeze forcing, and regional-scale mountain forcing, as well as the positive feedback between diabatic heating and heating-induced vorticity generation in the lower troposphere, which occurs via the meridional transfer of heat and planetary vorticity. Therefore, monsoons and deserts in the summertime subtropics coexist as twin features of the climate system produced by multi-scale circulations in association with various types of external forcing.

Acknowledgements. We thank three anonymous reviewers for their constructive suggestions. This study was jointly supported by CAS program KZCX2-YW-Q11-01, MOST program 2006CB403600 and NSFC Projects 40875034, 40821092, and 40810059005.

Topical Editor F. D'Andrea thanks three anonymous referees for their help in evaluating this paper.

\section{References}

Bounoua, L. and Krishnamurti, T. N.: Thermal dynamic budget of the five day wave over the Sahara Desert during summer, Meteor. Atmos. Phys., 47, 1-25, 1991.

Charney, J. G.: Dynamics of desert and drought in the Sahel, Q. J .Roy. Meteorol. Soc., 101, 193-202, 1975.

Chen, P., Hoerling, M. P., and Dole, R. M.: The origin of the subtropical anticyclones, J. Atmos. Sci., 58, 1827-1835, 2001.

Duan, A. M. and Wu, G. X.: Role of the Tibetan Plateau thermal forcing in the summer climate patterns over subtropical Asia, Clim. Dynam., 24, 793-807, 2005.

Eady, E. T.: The cause of general circulation of atmosphere, Roy. Meteor. Soc. Cent. Proc., 156-172, 1950.

Gill, A. E.: Some simple solutions for heat-induced tropical circulation, Q. J. Roy. Meteorol. Soc., 106, 447-662, 1980.

Hoskins, B. J.: Diagnosis of forced and free variability in the atmosphere, pp. 57-63, in: Atmospheric and Oceanic Variability, edited by: Cattle, H., Royal Meteorological Society, Bracknell, 1986.

Hoskins, B. J.: Towards a PV- $\theta$ view of the general circulation, Tellus, 43AB, 27-35, 1991.

IPCC: Chap. 8, Climate Change: The Scientific Basis, Contribution of Working Group I to the Third Assessment Report of the Intergovernmental Panel on Climate Change, edited by: Houghton, J. T., Ding, Y. H., Griggs, D. G., et al., Cambridge University Press, Cambridge and New York, 881 pp, 2001.

Kalnay, E., Kanamitsu, M., Kistler, R., et al.: The NCEP/NCAR 40-year reanalysis project, B. Am. Meteorol. Soc., 77, 437-471, 1996.

Kang, In-Sik, Jin, K., Lau, K. M., et al.: Intercomparison of atmospheric GCM simulated anomalies associated with the 1997/98, J. Climate, 15, 2791-2805, 2002.

Li, G. P., Duan, T. Y., Haginoya, S., et al.: Estimates of the bulk transfer coefficients and surface fluxes over the Tibetan Plateau using AWS data, J. Meteor. Soc. Japan, 79(2), 625-635, 2001. 
Lin, X. and Johnson, R. H.: Heating, moistening, and rainfall over the western Pacific warm pool during TOGA COARE, J. Atmos. Sci., 53, 3367-3383, 1996.

Liu, H. and $\mathrm{Wu}, \mathrm{G}$. X.: Impacts of land surface on climate of July and onset of summer monsoon: A study with an AGCM plus SSiB, Adv. Atmos. Sci., 14(3), 289-308, 1997.

Liu, Y. M., Wu, G. X. and Ren, R. C.: Relationship between the subtropical anticyclone and diabatic heating, J. Climate, 17, 682698, 2004.

Liu, Y. M., Wu, G. X., Liu, H., and Liu, P.: Condensation heating of the Asian summer monsoon and the subtropical anticyclone in the Eastern Hemisphere, Clim. Dynam., 17, 327-338, 2001.

Newman, M., Sardeshmukh, P. D., and Bergman, J. W.: An assessment of the NCEP, NASA, and ECMWF reanalyses over the tropical west Pacific Warm Pool, B. Am. Meteorol. Soc., 81, 4148, 2000.

Nigam, S., Chung, C., and Deweaver, E.: ENSO Diabatic Heating in ECMWF and NCEP-NCAR Reanalyses, and NCAR CCM3 Simulation, J. Climate, 13, 3152-3171, 2000.

Rodwell, M. R. and Hoskins, B. J.: Monsoon and the dynamics of deserts, Q. J .Roy. Meteorol. Soc., 122, 1385-1404, 1996.

Rodwell, M. R. and Hoskins, B. J.: Subtropical anticyclones and monsoons, J. Climate, 14, 3192-3211, 2001.

Tao, S. Y. and Chen, L.: A review of recent research on the East Asian summer monsoon in China, Monsoon Meteorology, edited by: Chang, C. P. and Krishnamurti, T. N., Oxford University Press, 60-92, 1987.

Wang, B.: The Asian monsoon, Praxis Publishing, Chichester, UK, Springer, pp. 787, 2006.

Webster, P. J., Magaña, V. O., Palmer, T. N., Shukla, J., Tomas, R. A., Yanai, M., and Yasunari, T.: Monsoons: processes, predictability, and the prospects for prediction, J. Geophys. Res., 103, 14451-14510, 1998.

Wu, G. X. and Liu, Y. M.: Thermal adaptation, overshooting, dispersion and subtropical anticyclone, I. Thermal adaptation and overshooting, Chin. J. Atmos., 24, 433-446, 2000.

Wu, G. X. and Liu, Y. M.: Summertime quadruplet heating pattern in the subtropics and the associated atmospheric circulation, Geophys. Res. Lett., 30, 1201, doi:10.1029/2002GL016209, 2003.
Wu, G. X., Zhang, X. H., Liu, H., et al.: The LASG global oceanatmosphere-land system model GOALS/LASG and its simulation study, App. Meteor., 8(spec.), 15-28, 1997a (in Chinese).

Wu, G. X, Li, W., Guo, H., Liu, H., Xue, J., and Wang, Z.: Sensible heat driven air-pump over the Tibetan Plateau and its impacts on the Asian Summer Monsoon, Collections on the Memory of Zhao Jiuzhang, edited by: Ye Duzheng, Chinese Science Press, Beijing, pp. 116-126, 1997b (in Chinese).

Wu, T.-W., Liu, P., Wang, Z., Liu, Y. M., Yu, R. C., and Wu, G. X.: The performance of atmospheric component model R42L9 of GOALS/LASG, Adv. Atmos. Sci., 20, 726-742, 2003.

Xie, P. and Arkin, P. A.: Analyses of global monthly precipitation using gauge observations, satellite estimates, and numerical model predictions, J. Climate, 9, 840-858, 1996.

Xue, Y. K., Sellers, P. J., Kinter, J. L., and Shukla, J.: A simplified biosphere model for global climate studies, J. Climate, 4, 345364, 1991.

Yamazaki, N., Kamahori, H., Yatagai, A., and Takahashi, K.: Current status of GAME reanalysis project and some preliminary results - Heavy precipitation on July 22, 1998 and diurnal variations of precipitable water, Proc. Int. GAME/HUBEX Workshop, Sapporo, Japan, GAME project, 24-29, 2000a.

Yamazaki, N. H., Kamahori, H., Yatagai, A., et al.: Release of GAME reanalysis data, Tenki, 47, 659-664, 2000b (in Japanese).

Yanai, M. and Li, C.: Mechanism of heating and the boundary layer over the Tibetan Plateau, Mon. Weather Rev., 122, 305323, 1994.

Yanai, M. and Wu, G.-X.: Effects of the Tibetan Plateau, in: The Asian Monsoon, edited by: Bin Wang, Springer, 513-549, 2006.

Yang, S., Webster, P. J., and Dong, M.: Longitudinal heating gradient: another possible factor influencing the intensity of the Asian summer monsoon circulation, Adv. Atmos. Sci., 9, 397410, 1992.

Yeh, T. C., Lo, S.-W., and Chu, P.-C.: The wind structure and heat balance in the lower troposphere over Tibetan Plateau and its surroundings, Acta Meteor. Sinica, 28, 108-121, 1957. 